\title{
O ATENDIMENTO HUMANIZADO EM UNIDADE PEDIÁTRICA: PERCEPÇÃO DO ACOMPANHANTE DA CRIANÇA HOSPITALIZADA ${ }^{1}$ HUMANIZED CARE IN A PEDIATRIC UNIT: THE PERCEPTION OF THE HOSPITALIZED CHILD'S COMPANION \\ LA ATENCIÓN HUMANIZADA EN UNA UNIDAD PEDIÁTRICA: LA PERCEPCIÓN DEL ACOMPAÑANTE DEL NIÑO HOSPITALIZADO
}

\author{
Paula Faquinello², Ieda Harumi Higarashi3, Sonia Silva Marcon ${ }^{4}$
}

${ }^{1}$ Trabalho apresentado à disciplina “Tópicos avançados: o cuidado nos diferentes ciclos de vida”, do Curso de Mestrado em Enfermagem
da Universidade Estadual de Maringá (UEM).
${ }^{2}$ Enfermeira. Especialista em Terapia Intensiva Adulto. Professora Temporária do Departamento de Enfermagem da UEM. Aluna não
regular do Mestrado em Enfermagem da UEM. Paraná, Brasil.
${ }^{3}$ Enfermeira. Doutora em Educação. Professora Adjunto e chefe do Departamento de Enfermagem da UEM. Paraná, Brasil.
${ }^{4}$ Enfermeira. Doutora em Filosofia da Enfermagem. Coordenadora do Mestrado em Enfermagem da UEM. Coordenadora do Núcleo
de Estudos, Pesquisa, Assistência e Apoio à Família da UEM. Paraná, Brasil.

PALAVRAS-CHAVE: Pediatria. Humanização da assistência. Equipe de assistência ao paciente. Acompanhantes de pacientes.
RESUMO: Estudo qualitativo desenvolvido com o objetivo de investigar a percepção do acompanhante da criança internada sobre a qualidade do atendimento prestado pela equipe hospitalar no tangente ao aspecto da humanização. Os dados foram coletados em outubro de 2006, junto a 20 acompanhantes (um pai, uma avó e 18 mães), em uma unidade pediátrica de um hospital-escola no Noroeste do Paraná, por meio de entrevista semiestruturada. Para o tratamento dos dados, empregou-se a técnica do Discurso do Sujeito Coletivo. Conclui-se que para a clientela em questão o atendimento humanizado no hospital está relacionado com a capacidade de abordar o paciente de forma holística e igualitária. As atitudes que conferem um caráter humanizado ao assistir, estão relacionadas com o estilo de comunicação adotado, ao passo que o atendimento não humanizado é traduzido por atitudes que valorizam as regras hospitalares, a falta de atenção e a baixa empatia por parte dos profissionais.
KEYWORDS: Pediatrics. Humanization of assistance. Patient care team. Patient escort service.

\begin{abstract}
This is a descriptive study of a qualitative nature, developed with the objective of investigating the perception of the companion of the hospitalized child as to the quality of care given by the hospital staff in regards to humanization. Data was collected during October of 2006 using semi-structured interviews with 20 companions (one father, one grandmother and 18 mothers) in the pediatric unit of a university hospital in northwestern Paraná, Brazil. For data treatment, the Collective Subject Discourse technique was used. It was concluded that for the clientele in question, humanized hospital care is related to the ability to approach the patient in a holistic and egalitarian manner. The attitudes that give the care a humanized character are related to the communication style adopted, while non-humanized care is defined by attitudes that value hospital rules, lack of attention, and low empathy from the professionals.
\end{abstract}

PALABRAS CLAVE: Pediatría. Humanización de la atención. Grupo de atención al paciente. Acompañantes de pacientes.
RESUMEN: El presente es un estudio descriptivo de naturaleza cualitativa, desarrollado con el objetivo de investigar la percepción del acompañante del niño hospitalizado, acerca de la calidad de la atención brindada por el equipo del hospital en lo concerniente a la humanización. Los datos fueron recogidos en octubre de 2006, a través de entrevista parcialmente estructurada con 20 acompañantes (un padre, una abuela y 18 madres), en una unidad pediátrica de un hospital-escuela en el noroeste de Paraná. Para el procesamiento de los datos se empleó la técnica del Discurso del Sujeto Colectivo. Con esta investigación se concluye que para la clientela en cuestión, la atención humanizada en el hospital está relacionada con la capacidad de ver al paciente en forma holística e igualitaria. Las actitudes que confieren un carácter humanizado en la atención, están relacionadas con el estilo de comunicación adoptado, mientras que la atención no humanizada se traduce en actitudes que valoran las reglas de los hospitales, la falta de atención y la poca empatía otorgada por los profesionales del ramo.
Sonia Silva Marcon

Endereço: Av. Colombo, 5790, Campus Sede da Universidade

Estadual de Maringá, Bloco 01

CEP 87.020-900 - Maringá, PR, Brasil.

E-mail: soniasilva.marcon@gmail.com

ieda1618@gmail.com
Artigo original: Pesquisa

Recebido em: 16 de abril de 2007

Aprovação final: 08 de outubro de 2007 


\section{INTRODUÇÃO}

A hospitalização é uma situação crítica e delicada na vida de qualquer ser humano, e tem contornos especiais quando se trata de um acontecimento na vida de uma criança, pois implica na mudança de rotina de toda a família.

A internação hospitalar traduz-se em experiência bastante difícil para o pequeno paciente, gerando ansiedade pela exposição da criança a um ambiente estressante, e onde o apoio para o enfrentamento destes sentimentos é bastante restrito, de tal forma que, uma das únicas fontes de segurança é representada pela presença dos pais. ${ }^{1}$

No sentido de mudar este panorama, muitas iniciativas vem sendo implementadas, contudo, estas são bastante recentes. O Brasil somente obteve avanço em relação à humanização da assistência à criança, após a publicação da Lei $N^{\circ} 8.069$, em 1990, regulamentando o Estatuto da Criança e do Adolescente, que em seu Artigo 12 preconiza que os estabelecimentos de saúde deverão proporcionar condições para a permanência de um dos pais ou responsável, em tempo integral, nos casos de internação de criança ou adolescente. ${ }^{2}$

Desde então, desenvolver um "cuidar-assistir" em pediatria significa envolver não só a criança nesse cuidado, mas abarcar também neste processo o seu universo relacional e social, de tal modo a considerar criança e família como um só cliente. O Ministério da Saúde (MS) define acompanhante como uma pessoa significativa para a criança, sendo um representante de sua rede social que vai acompanhá-lo durante a permanência no ambiente hospitalar. ${ }^{3}$

Os pais de crianças hospitalizadas, ao agirem como seus representantes legais, podem oferecer importante contribuição na identificação de falhas cometidas pelo sistema hospitalar, ${ }^{4}$ e que, invariavelmente, acabam por ocasionar um atendimento menos eficaz e errôneo. Tais situações exigem em sua maioria, mudanças ou reformulações de conduta; nem sempre reconhecíveis pelos profissionais de saúde.

Este mecanismo de controle social se faz cada vez mais importante e necessário se considerarmos que, com a evolução da ciência e o desenvolvimento de tecnologias mais avançadas no campo do suporte à vida, esquecemos por vezes, que o cuidado é, acima de tudo, realizado em e para seres humanos.

Além desta importância, no contexto da avaliação da atenção hospitalar, os pais exercem papel fundamental no contexto da hospitalização infantil, na medida em que representam a referência fundamental da criança, enquanto mediadores da relação terapêutica, fonte principal de segurança e de carinho, além de apoio imprescindível ao enfrentamento desta situação desafiadora que é a doença e o internamento.

Assim, nos defrontamos hoje com uma disparidade de conceitos e abordagens acerca do que vem a ser o hospital e a experiência da hospitalização: vista por alguns como um sistema que desconsidera a condição humana do paciente e onde o mesmo é comparado a uma máquina avariada, devendo portanto, receber passivamente tudo o que lhe é imposto..$^{5}$

Assim, há urgência em encontrar estratégias que propiciem soluções para uma melhora no atendimento ao ser humano. A questão do atendimento humanizado tem sido pauta das priorizações da iniciativa governamental, prova disso é o Programa Nacional de Humanização da Assistência Hospitalar (PNHAH), lançado pelo MS no ano de 2000. ${ }^{6}$

O referido programa prevê, entre várias formas de ação, a avaliação periódica da satisfação dos usuários e dos profissionais, envolvendo três aspectos fundamentais: a) capacitação permanente dos profissionais de saúde e criação de condições para sua participação na identificação das melhorias necessárias às suas condições de trabalho; b) criação de condições para a participação ativa do usuário na avaliação da qualidade dosserviços;c) participação da comunidade organizada como parceira dos agentes públicos em ações de apoio e acompanhamento dos serviços. ${ }^{6}$

O cuidar humanizado implica, por parte do cuidador, a compreensão ea valorização da pessoa humana enquanto sujeito histórico e social. ${ }^{7}$ Para isso, deve-se considerar acima de tudo que para desencadear um processo de humanização no ambiente hospitalar, não são necessários grandes investimentos ou adaptações no ambientefísico.É primordial que haja sensibilização com relação a problematização da realidade concreta, a partir da equipe multidisciplinar.

Nesse contexto, o presente trabalho objetiva investigar como os acompanhantes de crianças hospitalizadas avaliam a qualidade do atendimento prestado pela equipe de saúde de um hospital-escola, no tangente ao aspecto da humanização. Paraisso procuramosidentificar, apartir da perspectiva dos entrevistados, o conceito de atendimento humanizado em saúde no ambiente hospitalar e determinar atitudes e ações realizadas pela equipe de saúde e percebidas pelo acompanhante como atividades humanizadas e não-humanizadas. 


\section{METODOLOGIA}

Trata-se de um estudo descritivo, de natureza qualitativa realizado na unidade pediátrica de um hospital-escola do Noroeste do Paraná, que possui 15 leitos e tendo como característica predominante, a hospitalização de casos de longa permanência, em função da cronicidadedos diagnósticos. Esteperfil de atendimento é justificado em parte por se tratar de instituição hospitalar pública de referência para 115 municípios que compõem a macro-região noroeste do Paraná.

Os dados foram coletados por meio de entrevistas semi-estruturadas, realizadas ao longo do mês de outubro de 2006, junto a acompanhantes do referido setor pediátrico. O único critério de inclusão foi o aceite em participar do estudo, emitido pelos acompanhantes, mediante a assinatura de um Termo de Consentimento Livre e Esclarecido (TCLE) específico, e que culminou com a participação de um total de 20 acompanhantes, sendo um pai, uma avó e 18 mães. O instrumento de coleta de dados foi constituído por um roteiro semi-estruturado, composto por questões abertas e fechadas, dividido em duas seções. A primeira, referente à identificação e caracterização sócio-demográfica dos pacientes e informantes do estudo e a segunda, composta por questões amplas e abertas, cuja finalidade era a abordagem da temática central do estudo. Assim, os acompanhantes foram questionados sobre o entendimento que possuíam acerca do atendimento humanizado no hospital e em seguida, solicitados a exemplificarem momentos e/ou atitudes em que esta característica (da humanização ou de seu inverso) era identificada.

Os depoimentos obtidos durante os encontros foram gravados, transcritos e analisados pelo método do Discurso do Sujeito Coletivo (DSC). ${ }^{8}$ Este método consta de quatro figuras metodológicas: Expressão-Chave (ECH), Idéia Central (IC), DSC e Ancoragem (AC).

As ECHs são definidas como segmentos substanciais das falas literais dos sujeitos, e que definem o conteúdo e a seqüência do discurso elaborado em torno de uma idéia central. A IC consiste de uma expressão lingüística sintética que indica o "cerne" do discurso, ou seja, confere distinção a cada conjunto de expressões-chave, dando origem ao discurso do sujeito coletivo. Já o DSC é um discurso-síntese, constituído de um conjunto de expressões-chave, cujo conteúdo reflete a idéia central. Embora o DSC esteja redigido na primeira pessoa do singular, não representa uma experiência singular, mas sim, expressões homogêneas de vários sujeitos. ${ }^{8}$
Da mesma forma, o DSC neste contexto específico, fará referência por vezes, às experiências, sentimentos ou percepções dos acompanhantes (na maioria, mães), e em outros, às vivencias das crianças relatadas por estes acompanhantes. Isto se dá, fundamentalmente, em função do fortalecimento deste vínculo familiar, em especial, do binômio mãe e filho, nos contextos de enfrentamento que permeiam a experiência da hospitalização infantil.

Para este estudo a análise seguiu os seguintes passos: 1) leitura de cada depoimento singular; 2) extração das expressões-chave de cada depoimento; 3 ) agrupamento das expressões-chave homogêneas; 4) extração da idéia central de cada agrupamento das expressões-chave; 5) composição dos discursos do sujeito coletivo correspondentes a cada idéia central.

O desenvolvimento do estudo ocorreu em conformidade com o preconizado pela Resolução N. ${ }^{\circ}$ 196/96 do Conselho Nacional de Saúde - MS9 e o projeto de pesquisa foi aprovado pelo Comitê de Ética em Pesquisa Envolvendo Seres Humanos da Universidade Estadual de Maringá (UEM), sob o parecer N. ${ }^{\circ}$ 258/2006. Todos os participantes do estudo foram informados sobre os objetivos do estudo, tipo de participação desejada, livre opção de aceitar participar sem qualquer prejuízo na assistência prestada à criança e, após concordância, assinaram o TCLE em duas vias.

\section{APRESENTAÇÃO E DISCUSSÃO DOS RESULTADOS}

\section{Caracterizando o sujeito coletivo deste estudo}

A maioria dos acompanhantes na unidade pediátrica enquadrava-se na faixa etária de 24 a 35 anos (60\%), possuía baixa escolaridade (55\% não haviam completado o ensino fundamental e $25 \%$, possuíam o ensino médio incompleto). Grande parte das crianças esteve acompanhada predominantemente pela mãe (90\%), uma pelo pai e outra pela avó. A maioria das crianças $(75 \%)$ era cuidada no domicílio por suas próprias mães, fato este, coerente com a identificação de que $60 \%$ dos acompanhantes referiram como profissão a opção "donas de casa".

Com relação às crianças, cujos acompanhantes integraram os sujeitos desta pesquisa, observou-se que $40 \%$ delas experienciavam a hospitalização pela primeira vez. Em relação ao tempo de hospitalização, $25 \%$ estavam internadas há menos de 3 dias, $30 \%$ entre 4 e 7 dias, $25 \%$ de 8 a 14 dias e $20 \%$ há mais de 15 dias. Os motivos relacionados com a atual internação foram 
variados, sendo que, $40 \%$ estavam relacionados a problemas respiratórios, $20 \%$, a procedimentos cirúrgicos, $10 \%$ a problemas gastrintestinais, $10 \%$ a problemas renais, $10 \%$ por crise convulsiva, $5 \%$ por septicemia e $5 \%$ por prematuridade.

\section{Abordando a temática da humanização segun- do o DSC: o que se entende por "atendimento humanizado no hospital"?}

As manifestações dos sujeitos permitiram identificarváriasidéias centrais relacionadas ao entendimento que os acompanhantes possuem acerca do "atendimento humanizado no hospital", dando origem a três discursos coletivos.

\section{DSC 1 - Idéias associadas ao processo bumani- zado}

Nunca ouvi falar nisso. Acho que é tratar bem. O que eu entendo é os médicos ficarem conversando com a gente, cuidando, explicando o que tem de fazer. Se procura saber o que tá acontecendo... procurar explicar para a gente entender melhor. É ser bem cuidado, não falta os medicamentos na hora certa, tem a boa atenção das enfermeiras, tem a boa intenção dos médicos e tudo o que eles estão fazendo é por bom sentimento. Os funcionários, em geral, serem atenciosos; além de valorizar e tratar os pacientes e acompanhantes com respeito e educação. Responder bruto não é tratar com educação, e a pessoa tem que ser humana para atender as outras pessoas.

Idéias centrais: ser bem cuidado; ser bem atendido; ser valorizado; ser tratado com educação e com respeito; profissional deve ser atencioso e humano; não ser bruto; conversar e explicar conforme o entendimento dos acompanhantes;

\section{DSC 2 - Qualidades esperadas do profissional/ instituição}

Ah, eu acho que é o atendimento que vê mais o lado do paciente, que tenta entender mais o lado do paciente. Têm hospitais públicos com mais recursos do que outros hospitais, eles agem mais rápido nos exames e o atendimento é muito melhor, e não demoram para atender a gente. Todos ter um atendimento igual, e que atenda a todas as necessidades, pois conhecer as diferenças para lidar com as outras pessoas é difícil.

Idéias centrais: ver/entender o lado do paciente; atendimento igual a todos; atender todas as necessidades; rapidez no diagnóstico e alta hospitalar; conhecer as individualidades das pessoas; existem hospitais públicos que tem mais recursos e atendem melhor.
DSC 3 - Apesar de ser do Sistema Único de Saúde (SUS) é bom

Apesar de serpelo SUS, achei o atendimento muito bom. Uma vez. ele ficou internado em um hospital particular e não foi tão bem tratado como aqui.

Idéias centrais: apesar de ser do SUS ele foi bem tratado; o atendimento do HU é bom.

De acordo com os três DSC acima citados, a idéia que os acompanhantes apresentam sobre o atendimento humanizado no hospital, encontra-se um pouco vaga, gerando dúvidas acerca do conhecimento/familiaridade com esta terminologia.

O verbo humanizar significa "[...] tornar humano, agradável, civilizar". 10:238 Devido à origem e sentido intrínseco desta palavra, os entrevistados conseguiram associar a idéia de cuidado humanizado com o atendimento que vê e tenta entender mais o lado do paciente.

Tal percepção vem ao encontro da perspectiva assistencial holística e da definição de saúde global, na medida em que os discursos associam a atenção ao paciente, à idéia de que todos merecem receber um atendimento igual e que atenda a todas as necessidades (aspectos físicos, psicológicos, espirituais).

Acrescenta-se a isto, a surpresa na constatação dos participantes, acerca da qualidade encontrada no atendimento público em questão. Tal surpresa é atribuída à idéia prevalente no senso comum e nos meios de comunicação, ao compararem o atendimento público ao privado/particular, com uma desvantagem acentuada do primeiro no que tange à qualidade e efetividade do atendimento prestado à população.

Assim, outros aspectos positivos destacados pelos participantes, e que contribuem sobremaneira para uma avaliação satisfatória da qualidade de atenção, diziam respeito à disponibilidade de medicamentos adequados, dos recursos tecnológicos para diagnóstico, além do atendimento prestado pela equipe.

\section{Momentos ou atividades relacionadas com o cuidado humanizado}

Ao investigarmos em que momentos ou atividades desenvolvidas pelos profissionais de saúde o acompanhante conseguia perceber o "cuidado humanizado", tanto para consigo como o direcionado à criança, as manifestações apresentaram idéias centrais que permitiram a identificação de cinco grupos de DSC. 
DSC 1 - Os profissionais que atendem bem são os que gostam de trabalbar na área da saúde

Ah, é bumanizado quando tratam bem as crianças, principalmente a mãe, tratam com carinho e não são estúpidos nem mal educados. Têm algumas muito boas, que quando precisa, elas atendem. É o que gostam de fazer! E tem o momento que eles conversam com a gente. Tem um médico que atendeu ele muito bem, me explicava o que tava acontecendo e até mostrava as fotos, epedia se eu tinha mais alguma pergunta. Eu saía satisfeita, entendeu? Da minha parte, todos os profissionais são bons. Todas as vezes que interna, eles sempre trataram bem, são educados e prestativos. Eu gosto muito daqui, e o que eu percebo, é a atenção assim que chegou, tanto na parte do médico, da enfermaria, da limpeza, da comida, de tudo. A diferença que eu vejo é que do jeito que eles tratam uma mãe, eles tratam outra.

Idéias centrais: conversar com os acompanhantes; ser bem atendido; ser bem tratado; receber atenção; ser prestativo; tratar com carinho; não ser grosso/bruto; não ser mal educado; dar atenção para pessoa em todos os setores do hospital (enfermaria, limpeza, comida); os que tratam bem gostam do que fazem.

\section{DSC 2 - Dar importância para o que a mãe fala}

O cirurgião que atende a gente, ele é muito humano, e dá importância para o que a mãe fala. Ele atende no consultório particular e não cobra nada, além de ter aceitado fazer "as duas cirurgias ao mesmo tempo", que eu pedi. Sabe, a mãe conhece a criança melhor do que ninguém; e é complicado fazer duas cirurgias separadas, passar por anestesia e tudo mais.

Idéias centrais: dar importância para as informações fornecidas pelas mães; o cirurgião é humano, atende e não cobra, além de aceitar pedidos da mãe.

\section{DSC 3 - Deixar a mãe ver um filbo na Unidade de Terapia Intensiva (UTI) é um gesto de caridade}

Meu filho estava na UTI e geralmente não deixam a mãe ficar, mal deixa a mãe ver. Ah... sei lá, en acho que tem que ver como gesto de caridade. Porque a gente tá ali desesperada. Eu não imaginava que eles iam deixar eu ver, ainda mais quando vê a mãe nervosa assim. Graças a Deus, não foi o meu caso.

Idéia central: deixar a mãe ver o filho na UTI é um gesto de caridade.

\section{DSC 4 - Ter profissionais capacitados}

É pelo jeito que ele chegon aqui, en pensava que ia perder meu filho. Mas gracas a Deus e segundo o conhecimento dos médicos e enfermeiras, ele sain vivo.
Idéia central: os profissionais têm conhecimento para salvar vidas.

\section{DSC 5 - A prioridade é atender bem a criança}

Eles cuidaram bem de meu filho. Não de mim, pois não sou eu que estou internada. ciente.

Idéia central: a prioridade no cuidado é o pa-

As ações "humanizadas" desenvolvidas pela equipe de saúde são percebidas em termos das atitudes e comportamento dos profissionais, associados à percepção dos sujeitos de tratar-se de posturas de conotação vocacional (gostar do que fazem), ou associados com uma competência teórica e técnica adequada.

Com relação à observação do DSC 5, sobre a priorização de atender bem a criança, é preciso ressaltar que a compreensão atual do cuidado à criança, não pode excluir deste processo, a mãe e a família da criança. Esta compreensão se fundamenta, por umlado, na indissociabilidade destes elementos, compondo um único universo ou realidade sócio-psico-emocional e, por outro lado, na mútua influencia que exercem entre si, contribuindo positiva ou negativamente para a construção de uma relação terapêutica.

Assim, são inúmeros os estudos na área pediátrica que ressaltam a importância de considerar este olhar holístico, integrador e contextualizado enquanto alicerce fundamental da atenção humanizada. ${ }^{11-13}$

A humanização é retratada em termos da qualidade do relacionamento terapêutico e da relação de parceria estabelecida entre equipe e família. Termos como "gesto de caridade", "cuidar bem", "tratar com carinho e dar atenção" retratam bem a valorização destes aspectos. A capacidade e o interesse na comunicação dos profissionais também são ressaltados como características essenciais do cuidado humanizado.

Para as mães, conforme já identificado em outros estudos, ${ }^{14}$ as enfermeiras são vistas como memoráveis quando em seu cuidado levam em conta "as pequenas coisas", traduzidas em gestos e atitudes, e que proporcionam um suporte psíquico emocional e uma relação de ajuda, tornando a hospitalização uma experiência mais facilmente tolerável.

As "pequenas coisas” foram definidas em termos da preocupação dos profissionais em tratar os pacientes e familiares de modo individualizado, chamando as crianças pelo nome, abordando os familiares de um modo amigável/carinhoso, demonstrando amor e respeito por elas, usando o toque, o afago, uma entonação 
de voz suave e utilizando o olhar para transmitir uma variedade infinita de mensagens. Estas 'pequenas coisas', segundo os autores constataram, não dependem de tecnologia e de pesquisas farmacêuticas, porém fazem a diferença para mães e crianças hospitalizadas. ${ }^{14}$

\section{Ações/atividades não humanizadas}

Como último ponto de análise, as manifestações ou atitudes dos profissionais e do serviço, interpretadas pelos participantes como ação/atividade não humaniza$\mathrm{da}$, permitiram a formação de dois grupos de DSC.

\section{DSC 1 - Regras e burocracia hospitalar}

Olha, desde que ele nasceu, ele tem dificuldade prá sugar o líquido. E mesmo com esta dificuldade, eles não deixaram en dar "chuquinha". Eu sei que o hospital tem um projeto de amamentação. Mesmo com a pediatra recomendando e ele não estando bem, e ainda perdendo peso, a enfermeira responsável pelo projeto não abriu exceção. A manutenção do projeto era mais importante do que o meu filho! A não ser quando o meu filho teve que fazer um exame, mas dai surgiu uma urgência e colocaram na frente. Eu entendi por este lado, mas é muito enrolado para fazer os exames. Eu acho que eles deveriam ter adiantado, ficou marcado para hoje e depois, jogaram para amanhã. Eles estão "jogando" muito. Ele deveria terfeito já, porque eu só to esperando o resultado para poder ir para casa. Desde que internei, eles falaram que iam providenciar ambulância para a consulta que meu filho tinha marcado e que não podia perder. Mas chegou no dia, às seis horas da manhã, a enfermeira veio e perguntou se eu não tinha como levar ele. Eu achei que foi muita falta de consideração, porque desde o dia anterior eu estava perguntando e eles não me disseram nada. Além do mais, eu acho ruim a visita, eu moro longe e já é difícil ter o dinheiro da passagem, tem vezes que vem mais gente e pouca gente entra, e sópode entrar de um em um.

Idéias centrais: regras e burocracia hospitalar; demora na realização de exames.

\section{DSC 2 - Atendimento público é ruim: críticas a outros serviços}

O atendimento público na cidade onde eu morava é muito ruim. Nos postos de saúde, as enfermeiras são muito brutas, não atendem com calma, só na grosseria. Uma vez, fui consultar e a fila dobrava, de tão grande. E agendaram a consulta depois de uma semana. E também, não tem nem como a gente reclamar, porque se reclamar épior. Lá em outro hospital, era por volta de meia noite, en fui buscar um lençol porque a minha filha tinha feito xixi, e a enfermeira disse que eu teria de esperarpara depois das quatro da manhã, que o roupeiro ia abrir. A menina ficon sem o lençol e dormiu só no plástico. Além disso, ela tem que mamar toda hora para não dar convulsão, e a enfermeira falou que a cozinha tava fechada e não tinha como fornecer mamadeira. Tem hospital que é assim, na frente é uma coisa, por trás é outra; porque quando a minha filha mais velha ficou internada no mesmo hospital, só que tinha plano particular pela firma, era lençol, tinha o que comer, olhavam a criança. E quando eu internei no SUS, não tinha nada disso.

Idéias centrais: cidade onde eu morava as enfermeiras são brutas, não atendem com calma só na grosseria; se reclamar é pior; demora para atender.

De acordo com a percepção dos acompanhantes entrevistados, manifestado no DSC, o atendimento "não humanizado" está relacionado a diversos fatores, que vão desde a supervalorização das regras/rotinas hospitalares (manutenção de projeto amamentação; número restrito de pessoas no horário de visitas), até a falta de atenção individualizada e respeitosa por parte dos profissionais: tem uns médicos que nem olham pro paciente, vai examinar e nem rela na criança, e já vai dando a receita (Acompanhante 18).

Assim os relatos representam o inverso das atitudes relacionadas à humanização, de tal modo que o contato afetuoso, a informação, dá lugar a uma relação áspera, sem troca de olhar, sem o toque e a inexistência de esclarecimentos capazes de atenuar a angústia paterna/materna.

Embora o desejável fosse uma relação de cooperação e parceria entre profissionais e pais de crianças internadas, ainda é muito comum a existência de uma relação de dominação-subordinação, ${ }^{15}$ além disso, a despeito dos profissionais reconhecerem o direito da família em permanecer junto à criança, tendem a transformar este direito em um dever - de ficar com a criança e de cuidá-la, sendo assim percebidos como agente de trabalho. ${ }^{15}$ E qualquer comportamento dos pais que não correspondam a este modelo de agente de trabalho, assim como o fato de ser mais crítico e questionador, pode se constituir em fator de conflito e distanciamento com a equipe.

A falta de comunicação, o mecanicismo das ações e a empatia quase inexistente, também são apontados comofatores que caracterizama "não humanização" do atendimento prestado pelos profissionais: tem um médico ai que não fala nada para gente, e quando a gente pergunta as coisas ele parece que tem má vontade (Acompanhante 19); tem umas enfermeiras "ruins" e que vem com falta de educação e sem paciência (Acompanhante 06).

Diversos estudos já foram realizados com o intuito de definir o que realmente importa para os pais enquanto seus filhos estão hospitalizados. Nestes, 
foram identificadas questões relacionadas às necessidades físicas e emocionais, incluindo a importância da comunicação, do apoio, das informações, do respeito, da negociação no cuidado à criança, do controle da dor, do tempo de espera, das relações interpessoais, da participação nas decisões, da continuidade no tratamento, do envolvimento no cuidado, da competência e aparência profissional, do ambiente, entre outros. ${ }^{16-18}$

Assim, estes estudos parecem confirmar os achados do DSC nesta realidade específica de investigação. Destes relatos é possível derivar que os pais necessitam de informação sobre as condições de saúde do seu filho, de tal forma a poder lidar com a situação de forma mais equilibrada, controlando suas reações na medida em que lhe são fornecidos maiores subsídios e conhecimentos sobre o diagnóstico de seu filho. Quando a criança é acometida por uma doença, os pais são geralmente confrontados com um contexto médico/hospitalar/ tecnológico e emocional que não lhe é familiar e que raramente, está preparado para considerar suas necessidades. Isto significa que os pais, em muitas realidades, acabam sendo deixados à margem do processo terapêutico de seus filhos, sem apoio dos profissionais e sem respostas para suas perguntas e incertezas. ${ }^{19}$

Emboraalguns poucos relatos tenham se voltado a criticar negativamente o aspecto da humanização no serviço considerado, o estudo permitiulevantar lacunas deste processo no sistema de atenção à saúde como um todo, por meio da citação de outros contextos mais desfavoráveis no que tange ao aspecto da atenção humanizada, em todos os níveis do sistema.

\section{CONSIDERAÇÕES FINAIS}

Conforme a análise dos dados, percebemos que a humanização no ambiente hospitalar deve ser entendida não só na perspectiva dos cuidados e tecnologias disponibilizadas pelos profissionais e serviços de saúde. A humanização, coerentementeaoquesepreconizanaatualidade, é percebida pelos pais da criança hospitalizada, com um conjunto complexo de atitudes/ações motivada por um pensamento ético, humanitário, social e holístico.

A valorização da presença materna eum processo educativo, informativo, de mão dupla, entre acompanhante e equipe, é condição sine qua nom ao alcance de uma prática assistencial realmente humanizada e humanizadora. Neste sentido, os dados do estudo revelaram que as atitudes que conferem um caráter humanizado no processo de assistir estão relacionadas com o estilo de comunicação adotado, ao passo que o atendimento não humanizado é traduzido por atitudes que valorizam as regras hospitalares, a falta de atenção e a baixa empatia por parte dos profissionais.

É primordial relembrar que estudos desta natureza, nos quais se vislumbra o diagnóstico de uma dada realidade assistencial, têm seus benefícios extensivos à própria equipe de saúde einstituição investigada, na medida em que fornece indícios para melhor compreender as expectativas e necessidades da clientela, estabelecendo ações e metas para a qualificação do atendimento hospitalare aconseqüente melhoriada qualidade de vida e saúde das pessoas envolvidas neste processo.

Neste sentido, a valorização de estratégias como a escuta compreensiva, a comunicação verbal e não verbal, e a otimização das informações entre membros da equipe, e desta com a criança/família, aparecem como elementos essenciais deste processo de construção coletiva.

Além disso, criam-se oportunidades para que opiniões, percepções, sugestões e reclamações da clientela em estudo possam ser expressas de forma livre e autônoma, consolidando um espaço para o verdadeiro exercício da democracia e da cidadania. Como profissionais de saúde, precisamos buscar na pesquisa científica e nas diversas abordagens de "fazer ciência”, meios e estratégias que nos permitam olhar criticamente nossas realidades, identificando lacunas e caminhos de transformação.

\section{REFERÊNCIAS}

1 Faquinello P, Collet N. Vínculo afetivo mãe/criança na unidade de alojamento conjunto pediátrico. Rev. Gaúcha Enferm. 2003 Dez; 24 (3): 294-304.

2 Ministério da Saúde (BR). Estatuto da criança e do adolescente. Brasília (DF): MS; 1991.

3 Ministério da Saúde (BR), Secretaria-Executiva, Núcleo Técnico da Política Nacional de Humanização. HumanizaSUS: visita aberta e direito a acompanhante. Brasília (DF): MS; 2004.

4 Co JPT, Ferris TG, Marino BL, Homer CJ, Perrin JM. Are hospital characteristics associated with parenteral views of pediatric inpatient care quality? Pediat. 2003 Feb; 111 (2): 308-14.

5 Leshan L. O câncer como ponto de mutação: um manual para pessoas com câncer, seus familiares e profissionais de saúde. São Paulo (SP): Summus; 1992.

6 Ministério da Saúde (BR), Programa de Humanização da Assistência Hospitalar, Secretaria de Assistência à Saúde. Programas e relatórios. n. 20. Brasília (DF): MS; 2001.

7 BackesDS,LunardiFilhoWD,LunardiVL.Aconstruçãode umprocessointerdisciplinardehumanizaçãoàluzdeFreire. Texto Contexto Enferm. 2005 Jul-Set; 14 (3): 190-205. 
8 LefèvreF,Lefèvre AMC. Discurso do sujeito coletivo:um novo enfoque em pesquisa qualitativa (desdobramentos). Caxias do Sul (RS): EDUCS; 2003.

9 Ministério de Saúde (BR), Conselho Nacional de Saúde, Comissão Nacional de Ética em Pesquisa. Resolução N. ${ }^{\circ} 196$ de 10 de outubro de 1996: diretrizes e normas regulamentadoras de pesquisa envolvendoseres humanos. Brasília (DF): MS, 1996.

10 Scottini A. Dicionário escolar da língua portuguesa. Blumenau (SC): TodoLivro; 1998.

11 JacobY,Bousso, RS. Validaçãodeum modeloteóricousado no cuidado da família que tem um filho com cardiopatia. Rev. Esc. Enferm USP 2006 Set; 40 (3): 374-80.

12 Bousso RS. A experiência da família durante a cirurgia cardíaca do filho. Rev. Nursing 2006 Jun; 97 (8): 860-5.

13 Pettengill MAM, Angelo M. Identificação da vulnerabilidade da família na prática clínica. Rev. Esc. Enferm USP 2006 Set; 40 (2): 280-5.

14 GasquoineS. Mothering a hospitalized child: it's the 'little things' that matter. Jour. Child Health Care 2005 Sep; 9 (3):186-95.
15 Silva JB, Kirschbaum DIR, Oliveira I. Significado atribuído pelo enfermeiro ao cuidado prestado à criança doente crônica hospitalizada acompanhada de familiar. Rev. Gaúcha Enferm. 2007 Jun; 28 (2): 250-9.

16 Shields L, Kristensson-Hallström I. We have needs, too: parental needs during a child's hospitalisation. Online Brazilian Jour. Nursing [serial on the Internet]. 2004 Dec [cited 2006 Nov 2]; 3 (3): [about 15 p.]. Avaliable from: www.uff.br/nepae/objn303shieldsetal.htm

17 Rahi JS, Manaras I, Tuomainen H, Hundt GL. Meeting the needs of parents around the time of diagnosis of disability among their children: evaluation of a novel program for information, support, and liaison by key workers. Pediat. 2004 Oct;114 (4): 477-82.

18 Cooner JM, Nelson EC. Neonatal intensive care: satisfaction measured from a parent's perspective. Pediat. 1999 Jan; 103 (1): 336-49.

19 Starke M, Möller A. Parents' needs for knowledge concerning the medical diagnosis of their children. Jour. Child Health Care 2002 Dec; 6 (4): 245-57. 